\title{
AN EARLY WARNING SYSTEM FOR THE ON-LINE PREDICTION OF COASTAL STORM RISK ON THE ITALIAN COASTLINE
}

\author{
Mitchell Harley ${ }^{1}$, Andrea Valentini' ${ }^{2}$, Clara Armaroli ${ }^{13}$, Paolo Ciavola ${ }^{1}$, Luisa Perini ${ }^{3}$, Lorenzo \\ Calabrese $^{3}$ and Francesco Marucci ${ }^{3}$
}

\begin{abstract}
The ability to predict the imminent arrival of coastal storm risks is a valuable tool for civil protection agencies in order to prepare themselves and, if needs be, execute the appropriate hazard-reduction measures. In this study we present a prototype Early Warning System (EWS) for coastal storm risk on the Emilia-Romagna coastline in Northern Italy. This EWS is run by executing a chain of numerical models (SWAN, ROMS and XBeach) daily, with the final output transformed into a format suitable for decision making by end-users. The storm impact indicator selected for this site is the Safe Corridor Width (SCW), which is a measure of how much dry beach width is available for safe passage by beach users. A three-day time-series of the predicted SCW is generated daily by the prototype EWS. If the minimum SCW exceeds a certain threshold, a warning is issued to end-users via an automated email service. All available prediction information is also updated daily on-line. Over the one year that the EWS has been operating (June 2011 until June 2012), 13 "code red" and 16 "code orange" warnings have been issued, with the remaining 305 predictions indicating low hazard in terms of the SCW. The reliability of the predictions from the perspective of the end-user has meant that the EWS is currently being expanded to include the entire Emilia-Romagna coastline.
\end{abstract}

Keywords: Early Warning Systems, beach erosion, coastal risk, XBeach, Lido di Classe, Emilia-Romagna

\section{INTRODUCTION}

The last decade has seen some particularly severe coastal disasters, including Hurricane Katrina in New Orleans, the 2004 and 2011 tsunamis in the Indian Ocean and Japan and the 2010 Xinthia storm in France (Ciavola et al., 2011a). All of these events have brought to light the importance of an Early Warning System (EWS) in predicting and preparing for the arrival of coastal risks, thereby minimizing loss of life as well as damage to infrastructure. According to the UN International Strategy for Disaster Reduction, a properly designed EWS consists of four main elements: 1) risk knowledge and identification; 2) hazard monitoring and early warning/prediction; 3) dissemination and communication; and 4) response capability (UN/ISDR, 2006). With specific regards to coastal storm risks, the development of EWSs is still in its infancy. For example, a review of coastal management plans and civil protection schemes across Europe (Ferreira et al., 2009) found that operational approaches involving real-time observations or predictions are currently very limited. Furthermore, where such approaches exist, they are based on meteorological and/or offshore wave forecasts that do not take into account localized near-shore variability that can result in substantially different responses along the coast.

There is clearly large potential to improve the prediction of coastal risks (and hence operational civil protection schemes) by translating storm forcing predictions into morphological impacts and risk scenarios at vulnerable sites along the coast. Developments in storm erosion models such as XBeach (Roelvink et al., 2009) mean that more sophisticated schemes can now be realised. In this study we present a prototype EWS that has been operating in real-time on the coastline of Emilia-Romagna in Northern Italy since June 2011. It is one of nine prototype systems that have been developed across Europe as part of the MICORE project (Ciavola et al., 2011b). Following a description of the study site, the methodology of the prototype EWS in Emilia-Romagna is described. Statistics of the predictions issued since its inception are then presented. Finally, the system's advantages and limitations as well its future expansion are discussed.

\section{METHODOLOGY}

\section{Study Site: Emilia-Romagna, Northern Italy}

The Emilia-Romagna coastline is situated on the Adriatic Sea in Northern Italy and comprises 130 $\mathrm{km}$ (from the mouth of the Po River in the north to the townships of Riccione and Cattolica in the south) of predominantly sandy beaches. It is typically a low energy environment (mean $\mathrm{H}_{\mathrm{sig}} \approx 0.4 \mathrm{~m}$,

\footnotetext{
${ }_{1}^{1}$ Department of Earth Sciences, University of Ferrara, Via Saragat 1, Ferrara, FE, 44100, Italy

2 ARPA-SIMC HydroMeteoClimate Service of Emilia-Romagna, Viale Silvani 6, Bologna, BO, 40122, Italy

${ }^{3}$ Servizio Geologico, Sismico e dei Suoli, Regione Emilia-Romagna, Viale della Fiera 8, Bologna, BO, 40127, Italy
} 
a)

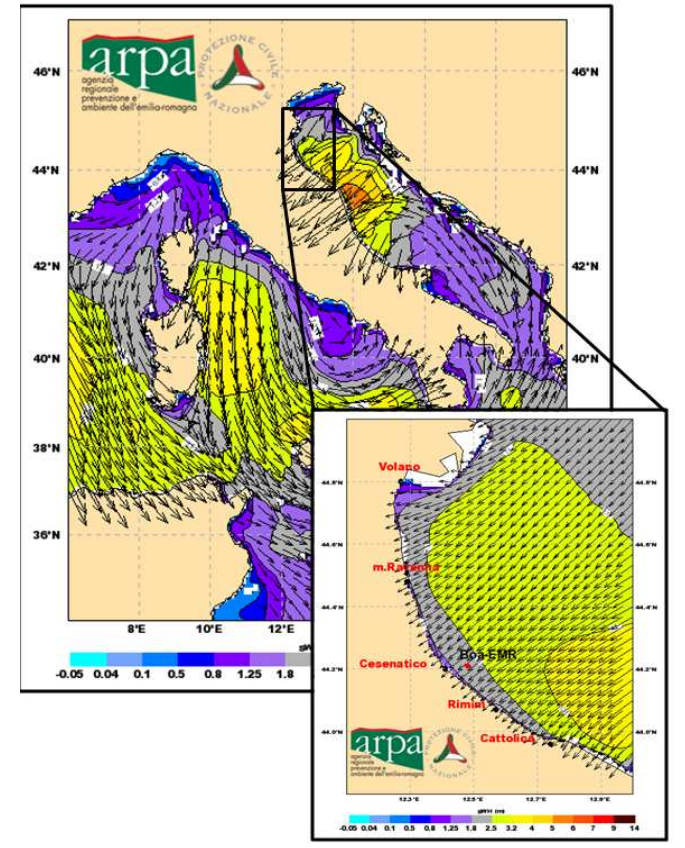

b)

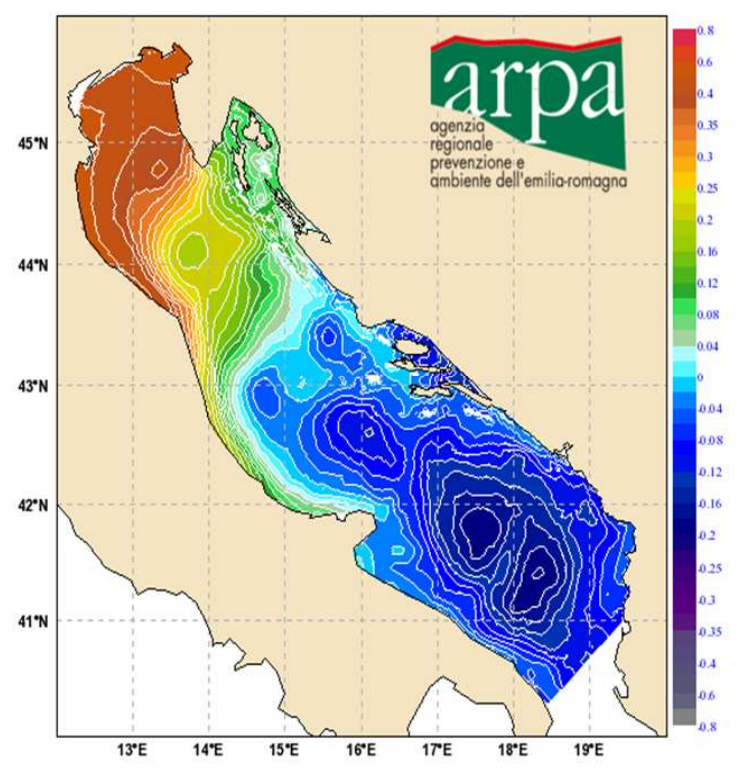

Figure 1. An example of: a) SWAN output of wave predictions for the Italian region and Emilia-Romagna (inset); and b) ROMS output of water level predictions for the Adriatic Sea

$\mathrm{T}_{\text {peak }} \approx 4 \mathrm{~s}$ ) with a semidiurnal and micro tidal regime (spring tidal range $=0.9 \mathrm{~m}$ ). Storm waves meanwhile of up to $3.3 \mathrm{~m}$ ( 1 in 1 year return period, Armaroli et al., 2009) and storm surge anomalies of up to $0.6 \mathrm{~m}$ ( 1 in 2 year return period, Masina and Ciavola, 2011) can occur, particularly in the winter months. Storm waves are predominantly from the east to northeast sectors and are associated with Bora weather conditions. Surge events meanwhile mainly occur during south-easterly (Scirocco) winds, which push water up the length of the Adriatic Sea. Waves generated from these SE winds however are generally not as large as those from Bora events due to both the lower strength of Scirocco winds and the sheltering of waves by Conero Headland to the south of the site.

The region is particularly vulnerable to coastal storms for several reasons. Firstly, the coastal hinterland is low-lying with a large section of it situated either close to or even below mean sea level. This issue has been exacerbated over the last 60 years by up to one meter of land subsidence, which has mostly been caused by post-war groundwater and gas extraction activities (Teatini et al., 2005). Secondly, there is a large amount of vulnerable beach front infrastructure situated along almost the entire Emilia-Romagna. This infrastructure is constructed to service the approximately six million tourists that visit the region's coastline every year (OTR Regione Emilia-Romagna, 2011). A consequence of this expansion in urban area is that very few sections of natural sand dunes remain and $57 \%$ of the coastline is in fact protected by coastal structures such as offshore breakwaters and groynes (Perini et al., 2008).

Within the current civil protection protocol for the Emilia-Romagna coastline, three-day wave and water level forecasts are undertaken daily by the HydroMeteoClimate Service of Emilia-Romagna (ARPA-SIMC) through its meteo-marine operational forecast system (Cacciamani et al., in press). Wave forecasts (see Fig. 1a) are performed using SWAN-MEDITARE (Valentini et al., 2007) forced with the $10 \mathrm{~m}$ wind output from the meteorological model COSMO-17 (COSMO Newsletter, 2004). A nested computation grid is used for SWAN runs, from an $8 \mathrm{~km}$ grid resolution for the entire Italian region to an $800 \mathrm{~m}$ grid specifically for Emilia-Romagna. Three-day water level forecasts meanwhile are undertaken using AdriaROMS (Chiggiato and Oddo, 2008). These water-level predictions are made using a grid of the Adriatic Sea with a regular $2 \mathrm{~km}$ resolution on a Lambert Conformal Conic cartographic projection.

A series of critical storm thresholds historically shown to have created significant morphological change and damage along the Emilia-Romagna coastline have been identified by Armaroli et al. (2012). These thresholds are as follows: 1) a significant wave height of $3 \mathrm{~m}$; 2) a sea water level (including surge and tidal effects) of $0.8 \mathrm{~m}$; and 3) a combined significant wave height and sea water level of $2 \mathrm{~m}$ 


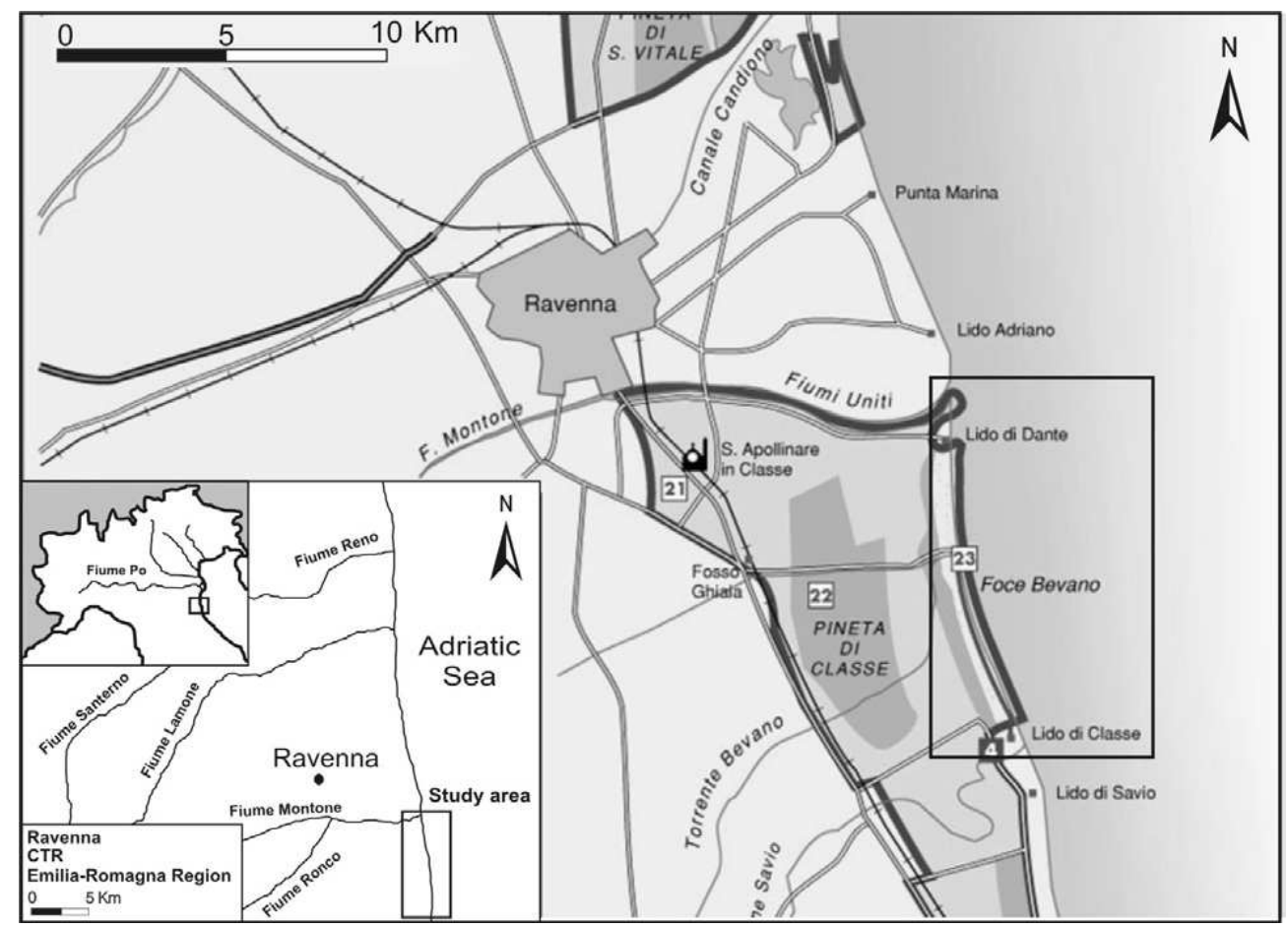

Figure 2. The site of the prototype Early Warning System, located in the natural dune area between the towns of Lido di Dante and Lido di Classe, Emilia-Romagna, Northern Italy

and $0.7 \mathrm{~m}$ respectively. When at least one of these three thresholds is predicted to be exceeded by the wave and water-level prediction models, the HydroMeteoClimate Service issues a weather warning to the civil protection authority. Based on all the available information and the risk evaluation, the authority then decides on whether or not to issue a civil protection alert. This alert is sent to local authorities and operation structures so that they can take the necessary actions indicated by their emergency plans.

\section{Prototype Early Warning System using XBeach}

The EWS presented in this paper extends the prediction system discussed above to incorporate hydro/morphodynamic interactions in the nearshore zone using XBeach. A simple approach has been initially adopted for the EWS, with complexity to be built into the system in the future. The specific site for this prototype system is a single cross-shore profile line located in the natural dune area between the towns of Lido di Dante and Lido di Classe, close to the city of Ravenna, Emilia-Romagna (Fig. 2). Topographic survey data (above MSL) to construct the XBeach grid were derived from a LiDAR flight undertaken in March 2009 and bathymetric data (below MSL) from a LiDAR flight in 2006. A photograph and plot of this profile line is shown in Fig. 3. The properties of this profile line are as follows:

- Grain size: $\mathrm{D}_{50}=0.2 \mathrm{~mm}, \mathrm{D}_{90}=0.3 \mathrm{~mm}$

- Dune crest height $=2.9 \mathrm{~m}$

- Dune foot height $=1.8 \mathrm{~m}$

- Distance between dune foot and $0 \mathrm{~m}$ contour $=33 \mathrm{~m}$

- Intertidal slope $=0.05$

- Cross-shore XBeach grid length $=4240 \mathrm{~m}$

- Variable cross-shore XBeach grid resolution from $20 \mathrm{~m}$ offshore to $1 \mathrm{~m}$ onshore

- $\quad$ Cross-shore XBeach grid points $=521$

- Maximum offshore water depth in XBeach grid $=10 \mathrm{~m}$ 

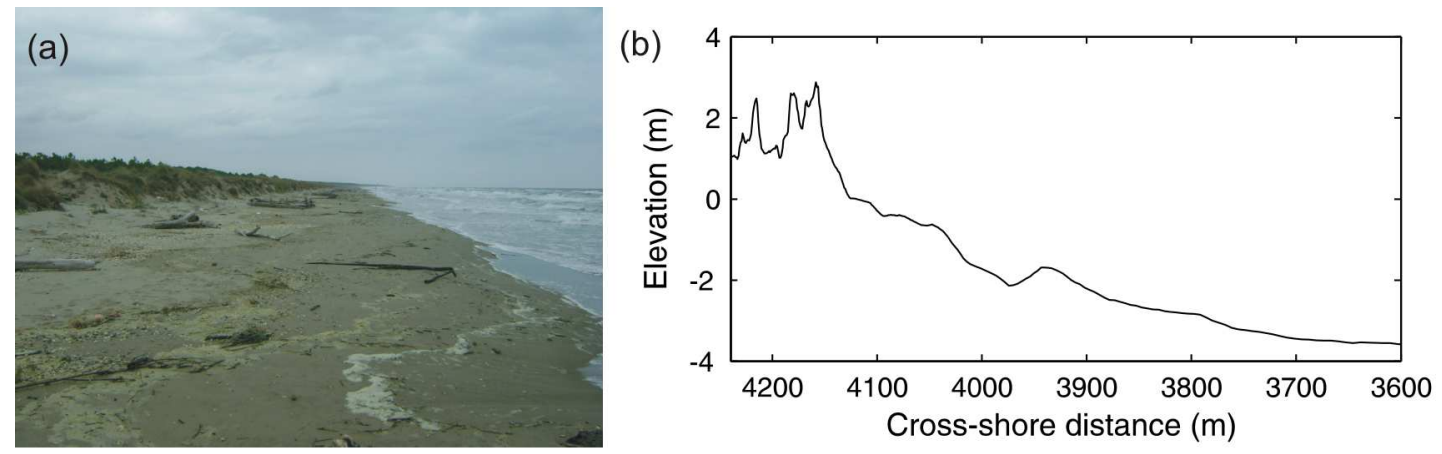

Figure 3. (a) Photo of the EWS profile line in the natural dune area of Lido di Classe, Emilia-Romagna (Photo: Edoardo Grottoli). (b) Plot of the profile line as used in XBeach.

Prior to incorporating the XBeach model into the prediction model chain, a series of XBeach calibration tests were first undertaken using pre- and post-storm survey data of events in December 2008 and March 2010 (Harley et al., 2011). These tests found that the model was particularly sensitive to the avalanching algorithm used by XBeach (the dry and wet slope thresholds). Optimum results based on the Brier Skill Score (BSS, Roelvink et al., 2009) were found when the wet slope threshold was increased from a default value of 0.3 to 0.5 . This yielded an average BSS of 0.17 at this profile line for the two storm events (note that a BSS $\leq 0$ means that the model performs worse or equal to the nochange prediction and BSS $=1$ represents a perfect prediction). A wet slope threshold of 0.5 was hence adopted for daily XBeach runs for the EWS.

The daily model prediction chain can therefore be summarized as follows:

1. Three-day predictions of the wave and water levels are run using the SWAN and ROMS models respectively. Data from the grid point closest to the profile line are then extracted

2. This data is then used as boundary conditions for the 1DH XBeach model run.

3. XBeach model output is then re-organized into a format suitable for end-users, as described in the following section.

\section{Translating model output for end-users: the Frame of Reference approach}

From an end-user perspective, raw output from the XBeach model is difficult to interpret with more than 100 available parameters to be extracted from just a simple one-dimensional model run. The "Frame of Reference" approach developed by van Koningsveld and Mulder (2004) was therefore adopted for the EWS in order to translate XBeach hydro/morphodynamics predictions into information useful for decision making. This approach focuses on the identification of so-called Coastal State Indicators (CSIs) that can be used instead of raw output to simply describe the dynamic-state of the coastal system (van Koningsveld et al., 2005). In the MICORE project progress was made applying the Frame of Reference to develop Storm Impact Indicators (SIIs) which can be used for benchmarking the state of the coastal system during the storm and decide if intervention is needed. This approach ensures the Early Warning Systems are designed in a way according to the criteria recommended by UN/ISDR (2006). The whole suite of SIIs developed by the MICORE project can be found in Ciavola et al. (2011b).

\begin{tabular}{|c|c|c|c|c|c|c|}
\hline $\begin{array}{l}\text { Strategic } \\
\text { Objective }\end{array}$ & $\begin{array}{l}\text { Operational } \\
\text { Objective }\end{array}$ & $\begin{array}{l}\text { Quantitative } \\
\text { State Concept }\end{array}$ & $\begin{array}{l}\text { Benchmarking } \\
\text { Desired State }\end{array}$ & $\begin{array}{l}\text { Benchmarking } \\
\text { Current State }\end{array}$ & $\begin{array}{l}\text { Intervention } \\
\text { Procedure }\end{array}$ & $\begin{array}{l}\text { Evaluation } \\
\text { Procedure }\end{array}$ \\
\hline $\begin{array}{l}\text { Prevent loss } \\
\text { of life due to } \\
\text { hazardous } \\
\text { maritime } \\
\text { conditions }\end{array}$ & $\begin{array}{l}\text { Signal that } \\
\text { the beach is } \\
\text { closed due to } \\
\text { hazardous } \\
\text { conditions }\end{array}$ & $\begin{array}{l}\text { Safe Corridor } \\
\text { Width (SCW): } \\
\text { defined as the } \\
\text { distance } \\
\text { between the } \\
\text { dune foot and } \\
\text { the water line }\end{array}$ & $\begin{array}{l}\text { Low hazard: } \\
\text { SCW is } \\
\text { greater than } \\
10 \text { meters, } \\
\text { Medium } \\
\text { hazard: SCW } \\
\text { is between } 5 \\
\text { and } 10 \\
\text { meters, } \\
\text { High hazard: } \\
\text { SCW is less } \\
\text { than } 5 \text { meters }\end{array}$ & $\begin{array}{l}\text { Time-series of } \\
\text { predicted } \\
\text { SCW }\end{array}$ & $\begin{array}{l}\text { Place } \\
\text { signage on } \\
\text { the beach } \\
\text { to indicate } \\
\text { beach is } \\
\text { closed }\end{array}$ & $\begin{array}{l}\text { Check that } \\
\text { signage was } \\
\text { placed and } \\
\text { no loss of life } \\
\text { occurred }\end{array}$ \\
\hline
\end{tabular}




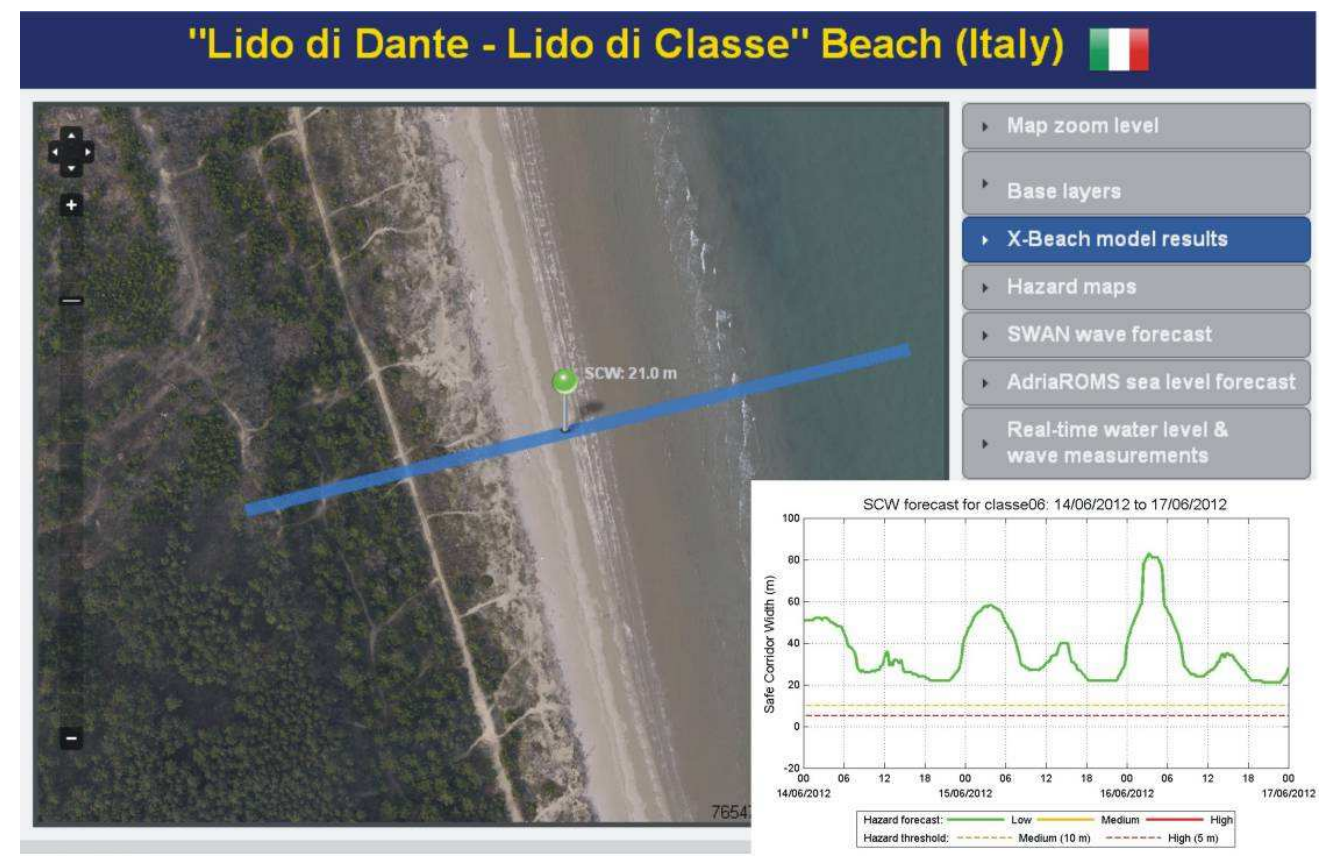

Figure 4. The Lido di Dante - Lido di Dante EWS website, which displays daily predictions of the Safe Corridor Width (access available at http://geo.regione.emilia-romagna.it/schede/micore/)

For this study one SII has so far been selected, referred to as the Safe Corridor Width (SCW). The SCW is a measure of how much dry beach width exists (i.e. between the dune foot and the waterline) to allow for safe passage by beach users. It is given by the equation:

$$
\operatorname{SCW}(\mathrm{t})=\mathrm{X}_{\mathrm{df}}-\mathrm{X}_{\mathrm{sl}}(\mathrm{t})
$$

where $\mathrm{X}_{\mathrm{df}}$ is the cross-shore position of the dune foot and $\mathrm{X}_{\mathrm{sl}}$ is the position of the water line that varies through time due to tidal variability, storm surge and wave setup/runup. If the SCW becomes too narrow then people could be putting their lives at risk by having no means of escaping the hazardous marine conditions.

Table 1 presents the application of the Frame of Reference methodology, as summarized by van Koningsveld et al. (2005), for the Safe Corridor Width at this site. The overall strategic goal is to prevent loss of life due to hazardous maritime conditions in the natural dune area where the profile line is located. Three different hazard levels for the SCW have been selected. High hazard is deemed when the SCW is less than $5 \mathrm{~m}$. Medium hazard meanwhile is when the SCW is between $5 \mathrm{~m}$ and $10 \mathrm{~m}$ and low hazard when it is greater than $10 \mathrm{~m}$. In the case of high hazard predictions, the appropriate action would be to place signage on the beach to indicate that the beach is closed.

A Matlab script has been developed that takes raw XBeach output from the three-day predictions and converts it into a three-day time-series of the SCW. A figure is automatically created by this script that presents this time-series, with the colors changing depending on the hazard level of (green $=$ low hazard, orange $=$ medium hazard, red $=$ high hazard). This figure enables the timing, duration and magnitude of the hazard level to be clearly identified.

\section{Communication and dissemination}

Communication and dissemination of the daily hazard predictions is in two forms. The first is a website which has been created to display all the relevant information (see Fig. 4), including the exact coordinate of the predicted minimum SCW over the following three-days as well as the associated three-day SCW time-series. Access to this site is available at http://geo.regione.emiliaromagna.it/schede/micore/. The second form is an automated email service, whereby an email is sent out to the relevant local authorities whenever there is a medium ("code orange") or high ("code red") hazard prediction in terms of the SCW. 


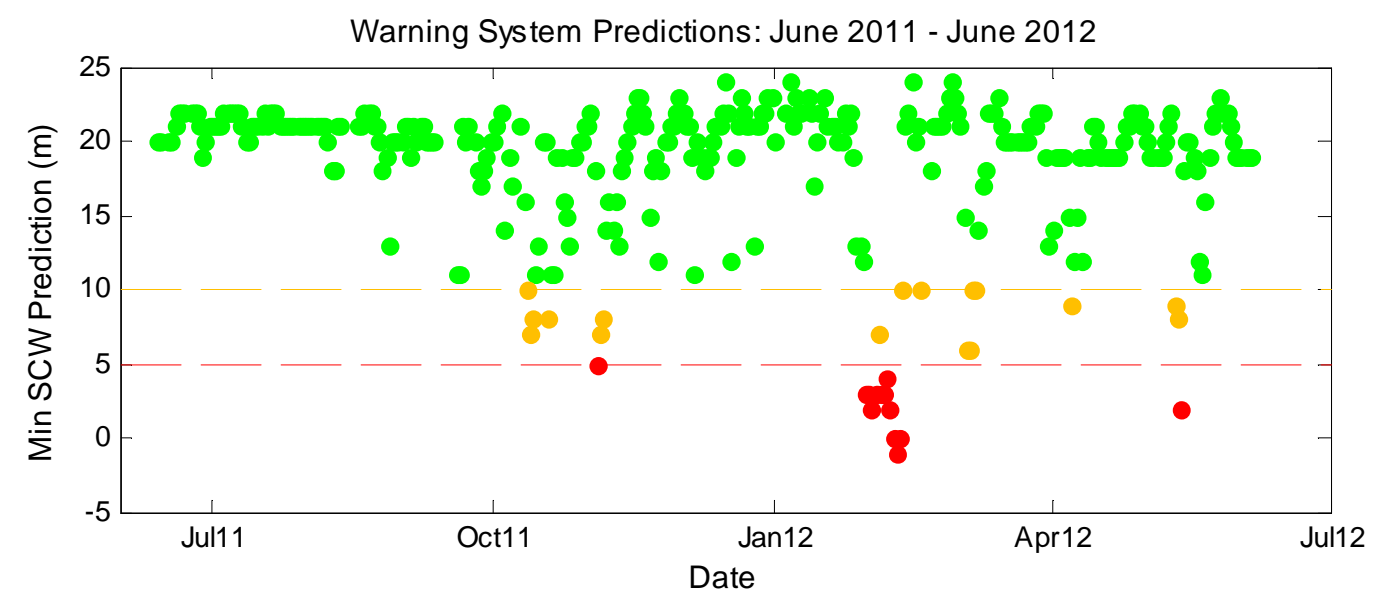

Figure 5. Predictions of the minimum SCW issued by the EWS from June 2011 to June 2012. The thresholds of the orange ( 10 meters) and red ( 5 meters) codes are indicated by dashed lines.

\section{RESULTS}

Fig. 5 presents the results of the minimum SCW prediction (for every successive three-day period) that have been issued daily between June 2011 and June 2012. A total of 334 predictions have been issued over this 359-day period, which equates to a data return rate of $93 \%$. The remaining $7 \%$ when no prediction was issued were mainly a result of server outages and not due to model run failures. From these 334 predictions, 13 "code red" warnings (or $4 \%$ of all predictions) and 16 "code orange" warnings $(5 \%)$ have been issued over this one year period, with the remaining 305 predictions $(91 \%)$ indicating low ("code green") hazard in terms of the SCW.

The minimum SCW predicted over this entire period was $-1 \mathrm{~m}$, which represents the waterline passing one meter beyond the dune foot and into the dune system itself. This prediction was issued on the 10 February 2012 for a storm event that occurred the following day. The SCW time-series for this prediction is shown in Fig. 6. Note that high-frequency fluctuations in this time-series are due to wave run-up variability and lower frequency fluctuations due to the time. Visual evidence (not shown) obtained from an Argus coastal imaging station just $4 \mathrm{~km}$ to the north of the EWS profile line at Lido di Dante (Armaroli and Ciavola, 2011) qualitatively agrees with this prediction, with large waves and runup clearly evident in the images coinciding with the predicted high hazard levels shown in Fig. 6. This is despite the cameras being located behind an offshore breakwater structure that protects the beach from offshore waves.

Overall statistics from the $334 \mathrm{XBeach}$ model runs over this one year period are summarized in Fig. 7. The daily minimum SCW prediction (Fig. 7a) has a mean of $18.5 \mathrm{~m}$ (i.e. low hazard). Additional information as to the predicted shoreline change $\triangle \mathrm{SL}$ (defined by the $0 \mathrm{~m}$ elevation contour) and the predicted volume change above mean sea level $(\Delta \mathrm{V})$ was also calculated and is shown in Fig. $7 \mathrm{~b}$ and $7 \mathrm{c}$ respectively. It is evident from these two histograms that the "no change" prediction (i.e. $\Delta \mathrm{SL}$ and $\Delta \mathrm{V}$ equal to 0 ) is overwhelmingly the most common and accounts for $78 \%$ of all predictions. The mean predictions of $\Delta \mathrm{SL}$ and $\Delta \mathrm{V}$ were $-1.3 \mathrm{~m}$ and $-0.4 \mathrm{~m}^{3} / \mathrm{m}$ respectively. Minimum predictions of $\Delta \mathrm{SL}$ and $\Delta \mathrm{V}$ meanwhile were $-10.6 \mathrm{~m}$ and $-10.9 \mathrm{~m}^{3} / \mathrm{m}$ respectively and occurred on the same date as that of the minimum SCW prediction (10 February 2012). Significantly, none of the 334 XBeach model runs predicted any accretion to occur.

\section{DISCUSSION AND CURRENT EWS EXPANSION}

\section{Advantages and limitations}

Through the addition of the XBeach model, information about nearshore processes can now be incorporated into the marine operational forecasting system currently in place in Emilia-Romagna. Hence whereas generic predictions such as high waves and/or surge levels need to be interpreted by taking into account prior knowledge of vulnerable coastal sections across Emilia-Romagna, this is done automatically in this prototype EWS by projecting the offshore predictions into the specific vulnerable coastal areas such as the natural dune area at Lido di Classe. In this way, factors that make a particular zone vulnerable such as a low dune crest, a previously eroded dune or a very narrow beach width are 


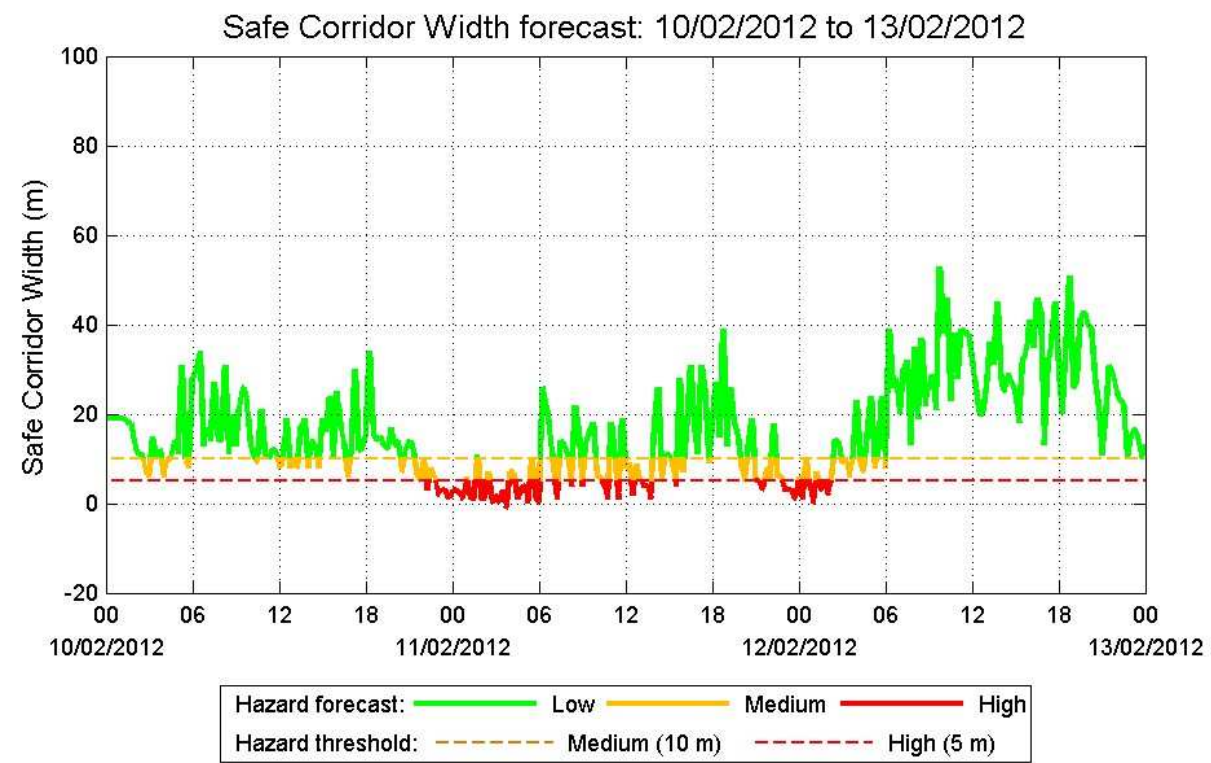

Figure 6. Three-day time series of the predicted Safe Corridor Width for a storm event in February 2012. Note that high-frequency fluctuations are due to wave run-up processes and lower frequency fluctuations due to the tide

already included in the forecast process. One dimensional profile runs are not computationally intensive in XBeach with each run taking approximately 3 minutes in computational time. Hence it is possible to apply this methodology to a whole number of vulnerable coastal sites across Emilia-Romagna.

The use of the Frame of Reference approach has shown to be particularly useful here in linking the numerical output with the needs of end-users. The Storm Impact Indicator selected in this study was the Safe Corridor Width, which is a measure of the dry beach width available and is a concept that is very important in coastal management worldwide. The Safe Corridor Width is not a direct output of XBeach but is instead calculated through a translation model using Matlab. The three-day time-series of the SCW, such as that shown in Fig. 6, enables the precise timing, duration and magnitude of the predicted hazard to be visualized, so that the appropriate hazard-reduction measures (i.e. placing beach signage to close the beach) can be performed accordingly by coastal managers.

One of the main limitations of the prototype EWS is that a fixed profile line is used as the initial profile for every model prediction. This means that the model predictions are likely to get worse over time as the initial profile progressively deviates from the real profile. This is particularly the case during evolving storm events of long duration ( $>1$ day). In these instances, the predicted minimum SCW has been observed to be more severe for model runs performed before the onset of the event than for those

(a)

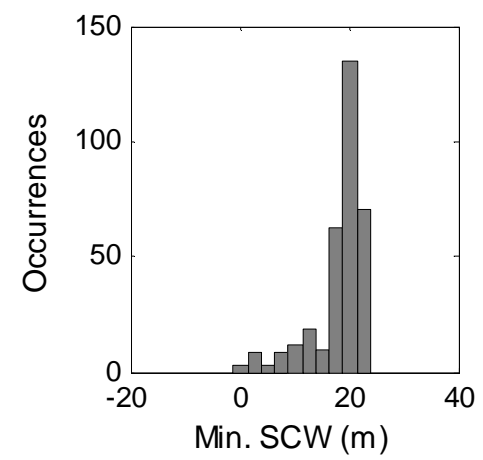

(b)

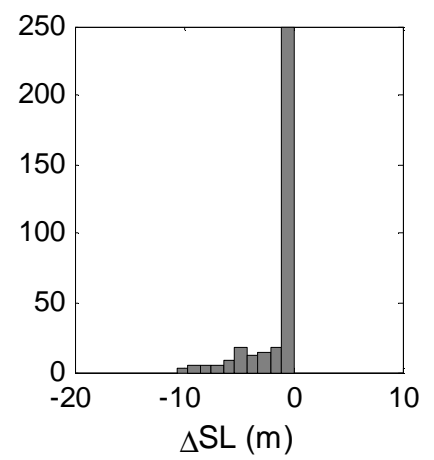

(c)

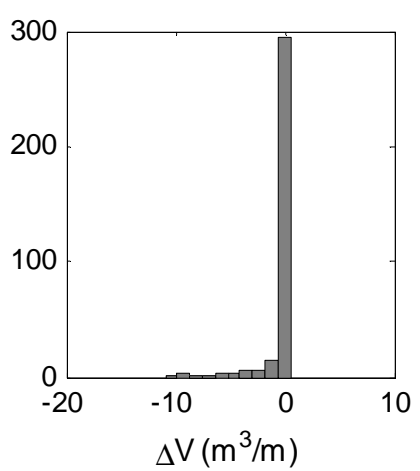

Figure 7. Statistics from the 334 XBeach model predictions between June 2011 and June 2012. (a) the predicted minimum Safe Corridor Width (SCW); (b) the predicted change in shoreline position ( $\Delta S L)$, as defined by the $0 \mathrm{~m}$ contour level; and (c) the predicted change in volume above mean sea level 


\section{Emilia Romagna Early Warning System}

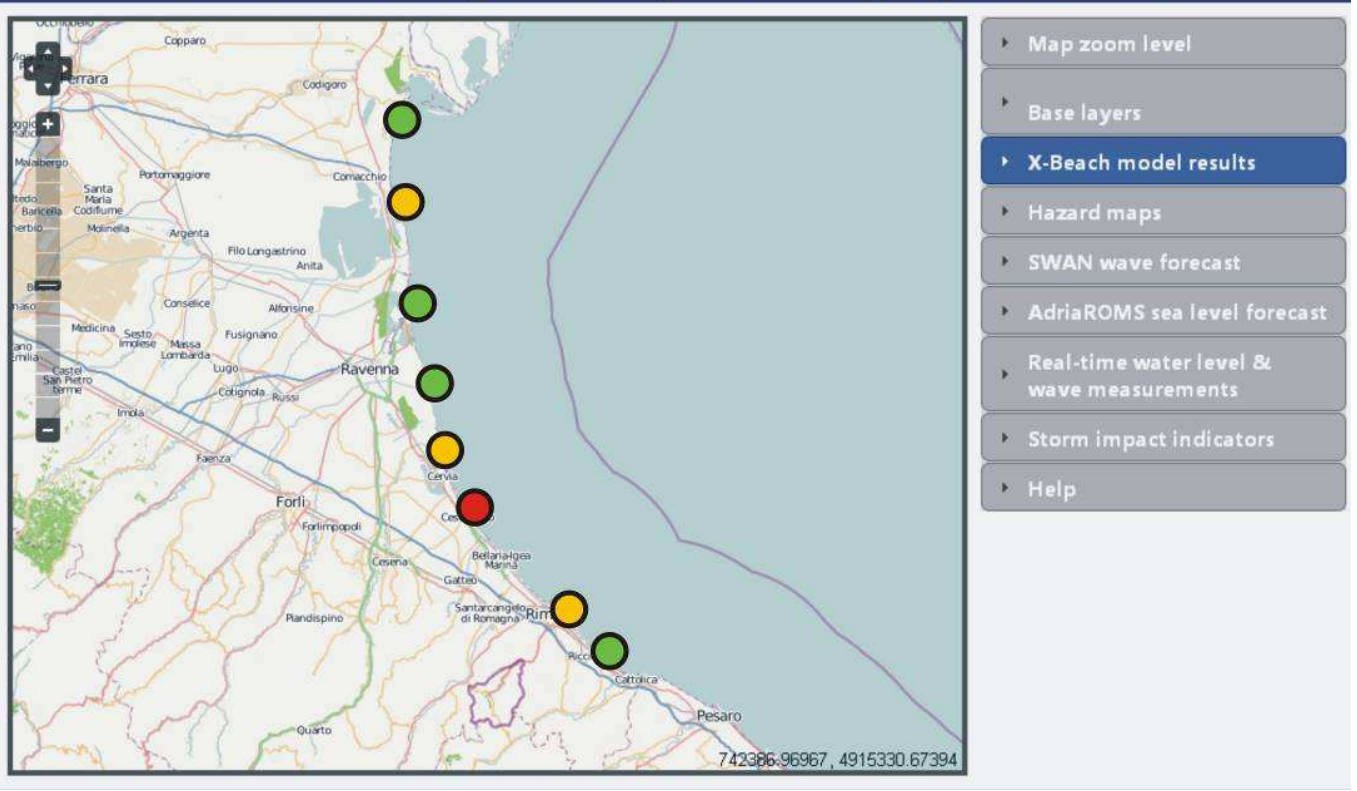

Figure 8. An example of a speculative forecast scenario for the expanded Early Warning System at eight different sites across Emilia-Romagna. The colors provide a quick summary for the coastal manager of the hazard level for each location for that particular day along the Emilia-Romagna coastline.

performed while the event is still evolving. This is because the former takes into account the whole event, whereas the predictions based on model runs performed during the storm event start from the initial profile that does not include the erosion that may have occurred at the start of the event.

In the special case of evolving storm events, a switch may be incorporated into the EWS to use the output from the day before as the initial profile line for that XBeach model run. It is not however appropriate to do this in all cases (i.e. during calm conditions). This is because XBeach in its current form does not model beach accretion (Ruiz de Alegria-Arzaburu et al., 2010), which means that the output using this strategy of continuously updating the initial profile using final model predictions would eventually tend towards an equilibrium storm profile.

Ideally, the initial profile should be surveyed as regularly as possible in order to maintain the accuracy of the predictions. In practice however this is both costly for end-users and resource intensive. This could be overcome by updating the profile using remote-sensing techniques (e.g. Stockdon and Holman, 2000; Aarninkhof et al., 2005) or data-model assimilation (e.g., van Dongeren et al., 2008), although these techniques are still being developed. Alternatively given the low computation time for each run, confidence intervals could be created around the initial forecasts by running ensembles of the initial bathymetry as well as forcing parameters. Such an approach is described by Baart et al. (2011).

\section{Current EWS Expansion}

The success of this prototype EWS in issuing automated and seemingly reliable (from an end-user perspective) warnings has meant that it is currently being expanded to include sites across the entire 130 $\mathrm{km}$ Emilia-Romagna coastline with more complex configurations. To take into account the alongshore variability in the natural dune area at Lido di Classe, i.e. the dune crest height, dry beach width and intertidal slope, an additional 10 profiles are being added one kilometer either side of the original profile line presented in this study. With these 11 profiles in close proximity to each other, the alongshore consistency in predictions of the SCW at a single site can therefore be tested.

A further 11 profile lines are currently being added at seven new sites roughly evenly spaced across the regional coastline. With these eight different sites it will be possible to present on a daily basis an overall picture of the predicted hazard level, such as that shown in Fig. 8. The color associated with each site provides a quick summary for the coastal manager as to the hazard level for that particular day. Further information can then be attained if needed by exploring the website. Potential also exists to incorporate this information into a format suitable for smartphones. 


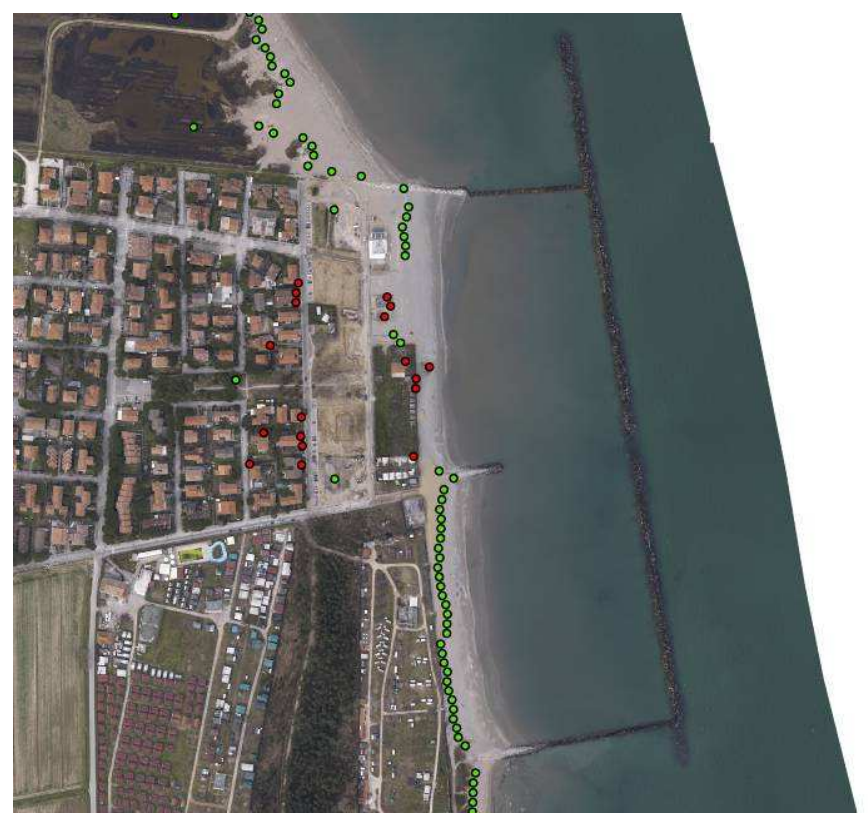

Figure 9. Result of a 2DH XBeach model run at Lido di Dante, Emilia-Romagna for an offshore significant wave height of $4 \mathrm{~m}$ and water level of $1.25 \mathrm{~m}$. Dots represent the position of the maximum waterline reached over the simulation, with green associated with low hazard in terms of proximity to buildings, orange medium hazard and red high hazard.

The 22 profiles that make up this expanded EWS do not cover the sections of the coast that are protected by offshore breakwaters. Harley et al. (2011) found that one dimension XBeach runs are not suited to areas with offshore breakwaters since the setup behind the breakwater in 1D simulations is significantly overestimated. Since offshore breakwaters make up the majority of the Emilia-Romagna coastline testing has begun on a two-dimensional XBeach prediction model at the protected area of Lido di Dante. Preliminary results of a simulation whereby the model was forced with constant $4 \mathrm{~m}$ waves and a water level of $1.25 \mathrm{~m}$ for 24 hours (an extreme scenario for this coastline) are shown in Fig 9. The maximum waterline reached over this simulation is shown in the northern cell of this protected area to go beyond the beach and into the township of Lido di Dante itself. Such a predicted scenario would most likely require hazard-reduction measures to be implemented by local authorities.

\section{CONCLUSION}

The coastline of Emilia-Romagna in Northern Italy is particularly vulnerable to coastal storm hazards due to the low-lying nature of its hinterland as well as the large amount of infrastructure situated along its coastline. Water-level and wave predictions for this $130 \mathrm{~km}$ stretch of coast are currently issued by the regional HydroMeteoClimate Service, which are then used to warn civil protection and local authorities. This study has presented an improvement to this procedure by incorporating nearshore processes and site-specific effects through the use of the numerical model XBeach. The prototype Early Warning System then translates the output from XBeach predictions into a format suitable for decision making by end-users. At present, one cross-shore profile line is used in the EWS and has been issuing hazard predictions since June 2011. While still in its preliminary phase, the reliability of the predictions from the qualitative perspective of end users has meant that the system is currently being expanded to include sites across the entire Emilia-Romagna coastline. With this expanded system it will not only be possible in the event of an oncoming storm event to provide a quick snapshot of the areas most vulnerable to coastal hazards along the coastline, but a detailed picture as to the likely timing, duration and magnitude of these hazards.

\section{ACKNOWLEDGEMENTS}

The research leading the development of the prototype early warning system has received funding from the European Community's Seventh Framework Programme under grant agreement n. 202798 assigned to the MICORE Project (www.micore.eu). The current maintenance and development of the system is financed through a contract from the Emilia-Romagna Region (Servizio Geologico Sismico e 
dei Suoli) to the Consorzio Ferrara Ricerche (scientist-in-charge P. Ciavola) and to ARPA-SIMC resources and availability to follow-up the project as Support Centre for the Civil Protection Agency of Emilia-Romagna.

\section{REFERENCES}

Aarninkhof, S.G.J., B.G Ruessink, and J.A. Roelvink. 2005. Nearshore subtidal bathymetry from timeexposure video images, Journal of Geophysical Research, 110, C06011

Armaroli, C., and P. Ciavola. 2011. Dynamics of a nearshore bar system in the northern Adriatic: A video-based morphological classification, Geomorphology, 126, 201-216.

Armaroli, C., P. Ciavola, M. Masina, and L. Perini. 2009. Run-up computation behind emerged breakwaters for marine storm risk assessment, Journal of Coastal Research, SI56, 1612-1616.

Armaroli, C., P. Ciavola, L. Perini, L. Calabrese, S. Lorito, A. Valentini, and M. Masina. 2012. Critical storm thresholds for significant morphological changes and damage along the Emilia-Romagna coastline, Italy, Geomorphology, 143-144, 34-51.

Baart, F., P.H.A.J.M. van Gelder, and M. Van Koningsveld. 2011. Confidence in real-time forecasting of morphological storm impacts, Journal of Coastal Research, SI64, 1835-1839.

Cacciamani C., M. Deserti, A. Valentini, S. Nanni, and T. Paccagnella. in press. ARPA-SIMC Operational Oceanography for the Emilia-Romagna Support Centre and Centre of Competence of the National Civil Protection System. I quaderni di ARPA - Speciale GNOO.

Chiggiato J. And P. Oddo. 2008. Operational ocean models in the Adriatic Sea: a skill assessment, Ocean Science, 4, 61-71.

Ciavola, P., O. Ferreira, P. Haerens, M. van Koningsveld, C. Armaroli, and Q. Lequeux. 2011a. Storm impacts along European coastlines. Part 1: The joint effort of the MICORE and ConHaz Projects, Environmental Science \& Policy, 14, 912-923.

Ciavola, P., O. Ferreira, P. Haerens, M. van Koningsveld, and C. Armaroli. 2011b. Storm impacts along European coastlines. Part 2: lessons learned from the MICORE project, Environmental Science \& Policy, 14, 924-933.

COSMO Newsletter. 2004. Operational Applications - ARPA-SIM (BOLOGNA), Deutscher WetterDienst (DWD), Offenbach, 6, 25-26.

Ferreira, O., P. Ciavola, C. Armaroli, Y. Balouin, J. Benavente, L. Del Rio, M. Deserti, L.S. Esteves, K. Furmanczyk, P.Haerens, A. Matias, L.Perini, R.Taborda, P. Terefenko, E. Trifonova, K. Trouw, N. Valchev, A. Van Dongeren, M. van Koningsveld, and J.J. Williams. 2009. Coastal Storm Risk Assessment in Europe: Examples from 9 study sites, Journal of Coastal Research, SI56, 16321636.

Harley, M., C. Armaroli, and P. Ciavola. 2011. Evaluation of XBeach predictions for a real-time warning system in Emilia-Romagna, Northern Italy, Journal of Coastal Research, SI64, 18611865.

Masina M., and P. Ciavola. 2011. Analisi dei livelli marini estremi e delle acque alte lungo il litorale ravennate. Studi Costieri, 18, 87-101.

OTR Regione Emilia-Romagna. 2011. Governance e Marketing Territoriale nel Turismo, Maggioli Editore, Ravenna, Italy, 324 pp.

Perini L., S. Lorito, and L. Calabrese. 2008. Il Catalogo delle opere di difesa costiera della Regione Emilia-Romagna. Studi Costieri, 15, 39-56.

Roelvink, D., A. Reniers, A. Van Dongeren, J. Van Thiel de Vries, R. McCall, and J. Lescinski. 2009. Modelling storm impacts on beaches, dunes and barrier islands, Coastal Engineering, 56, 11331152.

Ruiz de Alegria-Arzaburu, A., J.J. Williams, and G. Masselink. 2010. Application of XBeach to model storm response on a macrotidal gravel barrier, Proceedings of $32^{\text {nd }}$ International Conference on Coastal Engineering, ASCE, 466-480.

Stockdon H.F., and R.A. Holman. 2000. Estimation of wave phase speed and nearshore bathymetry from video imagery, Journalof Geophysical Research , 105 (C9), 22015-22033.

Teatini P., M. Ferronato, G. Gambolati, W. Bertoni, and M. Gonella. 2005. A century of land subsidence in Ravenna, Italy, Environmental Geology, 47 (6), 831-846.

UN/ISDR. 2006. Developing Early Warning Systems: A checklist, $3^{\text {rd }}$ International Conference On Early Warning, UN/ISDR, 1-13. 
Valentini, A., L. Delli Passeri, T. Paccagnella, P. Patruno, C. Marsigli, D. Cesari, M. Deserti, J. Chiggiato and S. Tibaldi. 2007. The sea state forecast system of ARPA-SIM, Bollettino di Geofisica Teorica e Applicata, 48 (3), 333-350.

van Dongeren, A., N. Plant, A. Cohen, D. Roelvink, M. Haller, and P. Catalan. 2008. Beach Wizard: Nearshore estimation through assimilation of model computations and remote observations, Coastal Engineering, 55, 1016-1027

van Koningsveld M., M. Davidson, and D. Huntley. 2005. Matching Science with Coastal Management Needs: The Search for Appropriate Coastal State Indicators, Journal of Coastal Research, 21 (3), 399-411.

van Koningsveld M., and J.P.M. Mulder. 2004. Sustainable coastal policy developments in the Netherlands: A systematic approach revealed, Journal of Coastal Research, 20 (2), 375-385. 